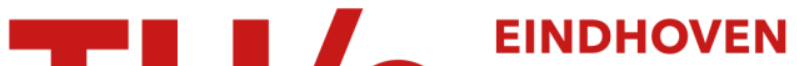

\section{Design and performance evaluation of the functional coating for air purification under indoor conditions}

\section{Citation for published version (APA):}

Lorencik, S., Yu, Q. L., \& Brouwers, H. J. H. (2015). Design and performance evaluation of the functional coating for air purification under indoor conditions. Applied Catalysis. B, Environmental, 168-169, 77-86.

https://doi.org/10.1016/j.apcatb.2014.12.012

DOI:

10.1016/j.apcatb.2014.12.012

Document status and date:

Published: 01/01/2015

\section{Document Version:}

Publisher's PDF, also known as Version of Record (includes final page, issue and volume numbers)

\section{Please check the document version of this publication:}

- A submitted manuscript is the version of the article upon submission and before peer-review. There can be important differences between the submitted version and the official published version of record. People interested in the research are advised to contact the author for the final version of the publication, or visit the $\mathrm{DOI}$ to the publisher's website.

- The final author version and the galley proof are versions of the publication after peer review.

- The final published version features the final layout of the paper including the volume, issue and page numbers.

Link to publication

\section{General rights}

Copyright and moral rights for the publications made accessible in the public portal are retained by the authors and/or other copyright owners and it is a condition of accessing publications that users recognise and abide by the legal requirements associated with these rights.

- Users may download and print one copy of any publication from the public portal for the purpose of private study or research.

- You may not further distribute the material or use it for any profit-making activity or commercial gain

- You may freely distribute the URL identifying the publication in the public portal.

If the publication is distributed under the terms of Article 25fa of the Dutch Copyright Act, indicated by the "Taverne" license above, please follow below link for the End User Agreement:

www.tue.nl/taverne

Take down policy

If you believe that this document breaches copyright please contact us at:

openaccess@tue.nl

providing details and we will investigate your claim. 


\title{
Design and performance evaluation of the functional coating for air purification under indoor conditions
}

\author{
S. Lorencik ${ }^{\mathrm{a}, \mathrm{b}}$, Q.L. Yu ${ }^{\mathrm{a}, *}$, H.J.H. Brouwers ${ }^{\mathrm{a}}$ \\ a Department of the Built Environment, Eindhoven University of Technology, P.O.Box 513, 5600MB Eindhoven, The Netherlands \\ ${ }^{\mathrm{b}}$ Materials innovation institute, Mekelweg 2, 2600 GA, Delft, The Netherlands
}

\section{A R T I C L E I N F O}

\section{Article history:}

Received 26 September 2014

Received in revised form 2 December 2014

Accepted 8 December 2014

Available online 12 December 2014

\section{Keywords:}

Photocatalytic efficiency

Carbon-doped titanium dioxide

Water-based top-coating

Nitric oxide

Direct incorporation

\begin{abstract}
A B S T R A C T
The present work aims to develop a photocatalytic coating for the improvement of indoor air quality. Two types of visible-light responsive photocatalysts (powder and suspension form) were applied into a water-based acrylic coating. The applied materials were characterized and the developed coatings were tested for the pollutant removal efficiency under visible-light irradiation.

The coatings containing a stabilized $\mathrm{C}-\mathrm{TiO}_{2}$ suspension showed nano-scale and uniform particle distributions. A UV treatment was found to be necessary, in order to expose the nano-photocatalytic particle and to promote the $\mathrm{NO}_{x}$ removal efficiency under visible light irradiation, from $5 \mathrm{~h}\left(7 \%\right.$ de- $\left.\mathrm{NO}_{x}\right)$ to $10 \mathrm{~h}\left(18 \%\right.$ de- $\left.\mathrm{NO}_{x}\right)$. In addition, the distribution and the incorporation of the catalyst were significantly improved in case of the coatings incorporating $\mathrm{C}-\mathrm{TiO}_{2}$ suspension.
\end{abstract}

(C) 2014 Elsevier B.V. All rights reserved.

\section{Introduction}

The quality of indoor air at homes, offices, schools, hotels, health care facilities and other private or public buildings or transportation vehicles, where people spend a large amount of their time (more than $80 \%$ ) is an essential determinant of healthy life, comfort and people's well-being. Hazardous substances emitted from buildings, construction materials, indoor equipment and/or due to human activities indoors (e.g., cooking, cleaning, smoking or heating) and pollutants from outdoors lead to a broad range of health problems and may even be fatal [1]. Indoor air pollution levels are very often higher than outdoors, particularly in air-tight buildings due to energy saving demands [2].

Photocatalytic oxidation (PCO) technology is considered as one of the potentially very efficient advanced oxidation processes for the improvement of the air quality by degrading inorganic and organic air pollutants [3-6]. The most used photocatalyst - titanium dioxide $\left(\mathrm{TiO}_{2}\right)$ (pure or modified) - has received considerable attention in the past decade due to its high PCO activity, high chemical stability, low toxicity and low cost $[7,8]$. Under the appropriate irradiation of photon energy, equal to or higher than its band gap energy, electron-hole pairs are generated on the $\mathrm{TiO}_{2}$. The photo-generated holes in the valence band and the electrons

\footnotetext{
* Corresponding author. Tel.: +31 40247 2371; fax: +31 402438595 .

E-mail address: q.yu@bwk.tue.nl (Q.L.Yu).
}

in the conduction band diffuse to $\mathrm{TiO}_{2}$ surface and they produce highly energetic hydroxyl radicals $\left(\mathrm{OH}^{\bullet}\right)$ and super-oxide radical anions $\left(\mathrm{O}_{2}{ }^{-}\right)$which can oxidize the adsorbed pollutants on the $\mathrm{TiO}_{2}$ surface [9]. The practical use of photocatalysis seems to be far less developed than the scientific interest, as reflected by the large number of scientific publications in comparison with the limited number of products that appear in the market [7].

Several building materials have been used as carriers for the application of photocatalytic materials, for example concrete $[3,10]$, mortar $[4,11]$, clays [12], polymers $[9,13,14]$, etc. It can be concluded that the application of photocatalytic materials is more beneficial while applied as a top layer rather than in the whole volume of the product, where most of the photocatalytic materials are hindered, not exposed to the environment and thus, not effective. This leads to an application of photocatalytic materials in coatings and since more strict regulation concerning the emissions of volatile organic compounds in coatings has been applied [15], water-based coatings appear to be a good solution. Incorporation of nano-materials to the conventional coatings produces new multi-functional coatings due to their small particle size and specific properties without significantly modifying their original properties. These coatings are termed "functional coatings" [16].

There are several techniques to incorporate nanoparticles onto or into a polymeric support. Based on the formation processes of the resulting composites, they could be generally divided into two categories: direct incorporation and in-situ synthesis [13]. Most of the in-situ techniques do not find the use in coatings with $\mathrm{TiO}_{2}$ 
as they require high calcination temperatures (e.g., $450^{\circ} \mathrm{C}$ [17] and higher), along with complex procedures and expensive instruments [18]. The direct incorporation method, on the other hand, has the advantages of convenience in operation, comparatively low cost and suitability for massive production [19,20]. Nano-materials and carriers are in this case prepared first separately, and then they are compounded by dispersion, solution, emulsion, fusion or mechanical forces $[9,21]$. In dry state, nanoparticles exist in the form of clusters: agglomerates, bonded at the corners and edges and/or aggregates with much stronger bonds. When added in a liquid, these bonds become even stronger. In order to achieve the best performance of the photocatalytic products, such as photocatalytic efficiency, optical behavior [22], aesthetic properties [23], etc., these particles need to be dispersed/broken as close as possible to their primary particle size [24] and stabilized to prevent re-agglomeration during or after the application.

The present study aims to develop a photocatalytic coating with the purpose of improving the indoor air quality. Wallpaper was chosen as the carrier of the photocatalyst, because of its wide application in indoor environments and its direct contact with ambient air. Due to the negligible ultraviolet irradiation indoors, application of a visible-light responsive photocatalyst was necessary. Within very few commercially available visible-light responsive photocatalysts, a carbon-doped titanium dioxide $\left(\mathrm{C}-\mathrm{TiO}_{2}\right)$ was used due to its good efficiency $[4,25]$. The effect of the direct incorporation of $\mathrm{C}-\mathrm{TiO}_{2}$ powder KRONOClean 7000 and a trial stabilized water-based suspension of KRONOClean 7000 into a protective water-based acrylic top coating was studied. The particle size and the stability of the photocatalysts were determined. The distribution of the photocatalytic particles incorporated in the water-based top-coating and applied on the wallpaper was analyzed, and the PCO efficiency of the developed coatings was investigated by the photocatalytic removal of an inorganic air pollutant nitric oxide (NO). A plug-flow experimental setup following ISO 22197-1 standard as a reference was used, and it was irradiated by visible light irradiation.

\section{Materials}

The carbon-doped titanium dioxide powder (KRONOClean 7000; designated KC7000) and the trial stabilized suspension of the KC7000 (designated SC40) were applied (all provided by Kronos International, Inc.) as photocatalysts. The $\mathrm{KC7000}$ is a $\mathrm{C}-\mathrm{TiO}_{2}$ powder with an anatase $\mathrm{TiO}_{2}$ content of $>87.5 \%$, density $(\rho)$ of $3.9 \mathrm{~g} / \mathrm{cm}^{3}$, crystallite size approximately $15 \mathrm{~nm}$, with an internal specific surface area $A>225 \mathrm{~m}^{2} / \mathrm{g}$, responsive to visible light up to nearly $550 \mathrm{~nm}$ [25] and application range of 4-9 pH (these information were acquired from data sheet of the provider). The SC40 is a water-based suspension containing around $40 \%$ of $\mathrm{C}-\mathrm{TiO}_{2}$ by mass, has a pH of $7-8\left(\right.$ at $20^{\circ} \mathrm{C}$ ), flash point $>90^{\circ} \mathrm{C}$, a density $(\rho)$ of $1.35-1.55 \mathrm{~g} / \mathrm{cm}^{3}$ (at $20^{\circ} \mathrm{C}$ ) and a dynamic viscosity $<800 \mathrm{mPa}$. A commercially used protective water-based acrylic top coating (TC54, designated TC) was used as the base material (provided by Polytex). Wallpaper carrier (provided by BN International) consisted of a paper substrate coated with a layer of polyvinyl chloride (PVC).

\section{Experimental}

\subsection{Photocatalyst dispersion}

In order to analyze the dispersibility of the photocatalysts, the particle size distribution (PSD) and the zeta potential ( $\zeta$-potential) was measured by a Zetasizer Nano ZS (Malvern) applying the dynamic light scattering (DLS) technique and a combination of electrophoresis and Laser Dopler Velocimetry, respectively.

Two samples containing KC7000 (KC1 and KC2) and a sample containing SC40 (SC) were prepared. The effect of the $\mathrm{pH}$ modification on the particle size and $\zeta$-potential of KC7000 was analyzed. $\mathrm{KC} 1$ and SC were mixed with demineralized water. KC2 containing KC7000 was modified by $1 \mathrm{M} \mathrm{NH}_{4} \mathrm{OH}$ solution during the mixing in order to modify its $\mathrm{pH}$. The $\mathrm{pH}$ modification was carried out in order to increase the $\zeta$-potential and consequently the stability of the dispersion. The $\mathrm{C}-\mathrm{TiO}_{2}$ concentration was fixed to $0.05 \%$ by mass in order to meet the concentration requirements of the analytical setup. Samples were prepared by adding the photocatalyst into demineralized water during the high-energy mixing under $4000 \mathrm{rpm}$ for a duration of $20 \mathrm{~min}$.

\subsection{Elemental analysis}

An elemental analysis was performed on TC and SC40 in order to determine their chemical composition. This was performed to quantify the amount of $\mathrm{TiO}_{2}$ in the SC40 and to analyze other components possibly interfering with the photocatalytic efficiency in SC40 and TC. The analysis was performed by an energy dispersive $\mathrm{X}$-ray fluorescence (EDXRF) spectrometer/Epsilon 3 range (PANalytical). The Omniam (standard-less) program was used for the analysis. The samples were dried and analyzed in a pressed powder form.

\subsection{Coating preparation}

The photocatalysts were incorporated into the top coating during the mixing phase. The best performing mixing method was chosen between a high-energy mixer (L5 M, Silverson) equipped with a square-hole high-sheer screen head and an ultrasonic homogenizer (UPS400, Hielscher). The mixing time and rotation rate were experimentally determined by the particle size analysis. The samples with the smallest particle size were chosen for further testing. The mixing volume $(V)$ of the coating was set as $100 \mathrm{~mL}$. Various formulations based on mass were used for the development of the PCO coating between the TC and SC40 or KC7000. Wallpaper with dimensions of $200 \times 100 \mathrm{~mm}^{2}$ was used as carrier. The developed coatings were applied as a final layer on top of the carrier. The coating application was performed by a drawdown coating method applying a wire-wound metering rod. The wire-wound metering rod type US4, coating with a wet thickness of $8 \mu \mathrm{m}$, was used for all coatings in order to precisely keep the dosage of the coating. The coatings were performed manually by applying the coating on the carrier and drawing it down with the wire-wound metering rod using an adequate and uniform force and speed. The coating thickness was governed by the cross-sectional area of the grooves between the wire coils of the rod. The groove between the wires determined the precise amount of coating material that passed through. The hardening of the coatings was performed by an infrared irradiation (IR) generated by an infrared dryer TEXFLASH (Acos Graf) with a $6000 \mathrm{~W}$ infrared heat source. The measured temperature on the surface of the irradiated coatings after $20 \mathrm{~s}$ under the full power of the IR dryer was about $150^{\circ} \mathrm{C}$. All samples were treated the same way during the coating application and curing phase. Firstly, the carrier was pre-heated by IR for $10 \mathrm{~s}$; then the coating was applied; and subsequently cured by IR for $20 \mathrm{~s}$. After the curing phase, the coated samples were kept in the dark until further actions. The $\mathrm{C}-\mathrm{TiO}_{2}$ dosage was calculated and measured by a series of mass measurements of wallpaper carriers before and after the coating application. Fig. 1 illustrates the experimental scheme.

The KC7000 powder was dispersed in demineralized water prior to the incorporation into the top coating by a high-energy mixer under 4000 rotations per minute (rpm) for a duration of $20 \mathrm{~min}$. The 


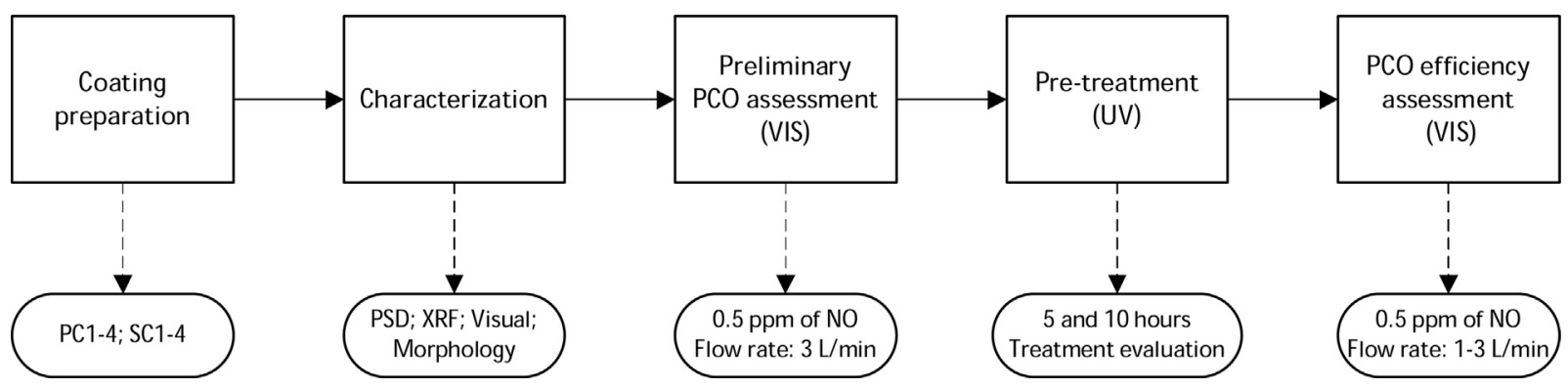

Fig. 1. Experimental scheme.

Table 1

$\mathrm{C}-\mathrm{TiO}_{2}$ amount and dosage.

\begin{tabular}{lllllllll}
\hline & PC10 & PC20 & PC30 & PC40 & SC10 & SC20 & SC30 & SC40 \\
\hline $\mathrm{C}-\mathrm{TiO}_{2}$ & 0.13 & 0.26 & 0.39 & 0.52 & $0.80^{*}$ & $0.60^{*}$ & $0.40^{*}$ & $0.20^{*}$ \\
{$\left[\mathrm{mg} / \mathrm{cm}^{2}\right]$} & & & & & & & & \\
\hline
\end{tabular}

* Contains surfactant.

as prepared dispersion was afterwards incorporated in a drop-wise fashion into the top coating during the high-energy mixing under $5000 \mathrm{rpm}$ for duration of $10 \mathrm{~min}$. Several coating designs were carried out. The samples containing 10,20 and $30 \%$ of $\mathrm{C}-\mathrm{TiO}_{2}$ by the mass of the binder (top-coating) were designated PC10, PC20 and PC30, respectively. The sample containing KC7000 (40\% by mass) dispersion without the binder was designated PC40 and the dosage was calculated as $0.52 \mathrm{mg} / \mathrm{cm}^{2}$. The SC40 was used as received and it was incorporated into the top coating in a drop-wise fashion during the high-energy mixing. The mixing was performed under $5000 \mathrm{rpm}$ for a duration of $10 \mathrm{~min}$. The samples containing 10, 20 and $30 \%$ of $\mathrm{C}-\mathrm{TiO}_{2}$ based on the mass of the binder were designated SC10, SC20 and SC30, respectively. The pure SC40 suspension was designated SC40 and the dosage was calculated as $0.80 \mathrm{mg} / \mathrm{cm}^{2}$. The $\mathrm{C}-\mathrm{TiO}_{2}$ dosages of the developed coatings are listed in Table 1 .

These relatively low dosages were chosen in order to maintain the transparency of the coatings and as well not to significantly raise the price of the final product. The reason for higher dosage in case of SC10-40 was the amount of the surfactant, as will be discussed.

\subsection{Morphology analysis}

The morphology of the samples was analyzed by a QUANTA FEG scanning electron microscope (FEI Company). The morphology analysis was performed initially on the wallpaper carrier and wallpaper coated by the top coating, SC40 or PC40. Samples for the analysis were prepared by coating the testing sample and curing it by the infrared irradiation. Moreover, the morphology analysis was carried out on the developed coated samples SC10-30 and PC10-30.

\subsection{Photocatalytic efficiency assessment}

The photocatalytic efficiency was assessed by the $\mathrm{NO}_{x}$ removal experiments using a plug-flow experimental setup. Nitric oxide (NO) was used as a model pollutant and it was mixed with a synthetic air and adjusted to the desired concentration and the flow rate. The low concentration $(0.5 \mathrm{ppm})$ of the pollutant and various flow rates $(1-3 \mathrm{~L} / \mathrm{min})$ were chosen in order to better represent the real conditions in indoor environment. The applied light source was composed of three fluorescent cool daylight lamps of $25 \mathrm{~W}$ each, emitting a visible light irradiation with the wavelength $400-700 \mathrm{~nm}$ and adjusted intensity of about $10 \mathrm{~W} / \mathrm{m}^{2}$. The experimental conditions, such as the pollutant concentration, flow rate, humidity and light intensity were fully controlled. The temperature and the humidity were measured at the inlet of the reactor. The outlet concentration of $\mathrm{NO}$ and $\mathrm{NO}_{2}$ were measured and interpreted as $\mathrm{NO}_{x}$ concentration. Fig. 2 shows the scheme of the plug-flow experimental setup.

The pollutant concentration was measured by an online $\mathrm{NO}_{x}$ analyzer APNA-370 (Horiba). The APNA-370 continuously monitors the NO concentration using a cross-flow modulated semi decompression chemiluminescence method. The concentration measurement was performed automatically every $5 \mathrm{~s}$ with a sampling flow rate of $0.8 \mathrm{~L} / \mathrm{min}$.

The amount of $\mathrm{NO}_{x}\left(\mathrm{NO}+\mathrm{NO}_{2}\right)$ removed was determined by using the following equation:

$\mathrm{NO}_{x}$ degradation $=\frac{\left[C_{\mathrm{NO}_{x}}\right]_{\text {in }}-\left[C_{\mathrm{NO}_{x}}\right]_{\text {out }}}{\left[C_{\mathrm{NO}_{x}}\right]_{\text {in }}} \times 100[\%]$

where the initial concentration $\left[C_{\mathrm{NO}_{x}}\right]_{\text {in }}$ was taken as an average value of 5 min before turning on the light. The outlet concentration $\left[C_{\mathrm{NO}_{x}}\right]_{\text {out }}$ was taken as an average value of the last 5 min of the irradiation period. The average values were taken due to slight

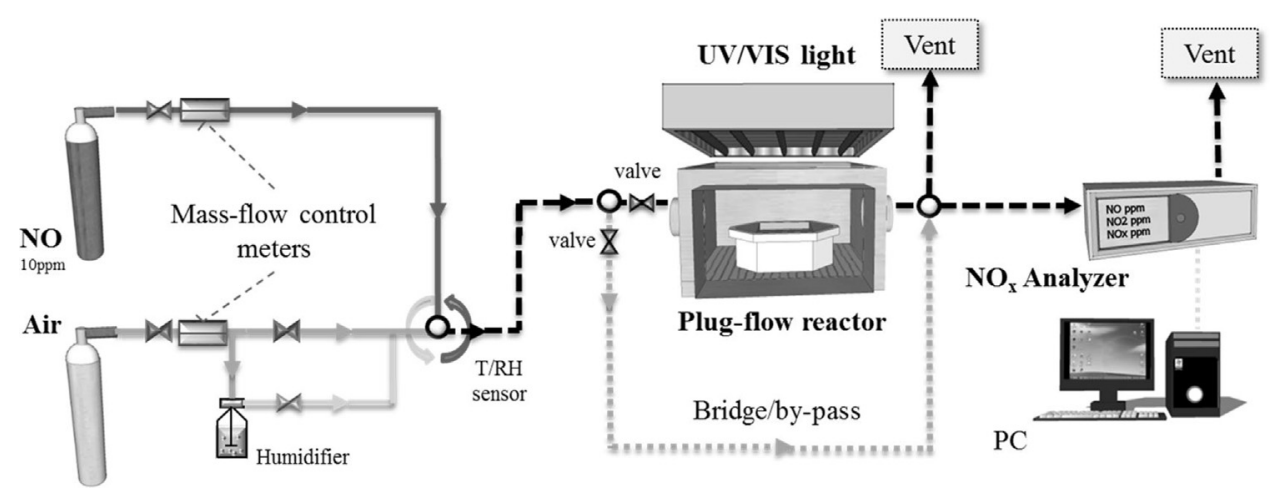

Fig. 2. Scheme of the plug-flow experimental setup. 
Table 2

Results of the particle size and $\zeta$-potential analysis of KC1, KC2 and SC.

\begin{tabular}{llll}
\hline & $\mathrm{pH}[-]$ & Average particle size & $\zeta$-potential $[\mathrm{mV}]$ \\
\hline $\mathrm{KC} 1$ & 4.5 & $2.13 \mu \mathrm{m}$ & -14 \\
$\mathrm{KC} 2$ & 8.5 & $2.20 \mu \mathrm{m}$ & -38 \\
$\mathrm{SC}$ & 7.4 & $63 \mathrm{~nm}$ & -33 \\
\hline
\end{tabular}

fluctuation of the concentrations, in order to better represent the efficiency.

The reaction mechanism of PCO of $\mathrm{NO}_{x}$, as described by Yu et al. [26], is shown below. Firstly, the photocatalyst needs to be photoactivated by the light of appropriate wavelength, which will result in the generation of electron/hole pairs:

$\mathrm{TiO}_{2}+h v \rightarrow \mathrm{e}^{+}+\mathrm{h}^{-}$

This is followed by the adsorption of the reactants $\left(\mathrm{H}_{2} \mathrm{O}, \mathrm{O}_{2}, \mathrm{NO}\right.$, $\mathrm{NO}_{2}$ ) onto the photocatalyst. The adsorption of $\mathrm{H}_{2} \mathrm{O}$ and $\mathrm{O}_{2}$ leads to the trapping of the generated holes and electrons and consequent generation of hydroxyl radicals and superoxides:

$\mathrm{h}^{+}+\mathrm{H}_{2} \mathrm{O} \rightarrow \mathrm{OH}^{\bullet}+\mathrm{H}^{+}$

$\mathrm{e}^{-}+\mathrm{O}_{2} \rightarrow \mathrm{O}_{2}^{-}$

Afterwards, the adsorbed pollutants can be oxidized by these radicals:

$$
\begin{aligned}
& \mathrm{NO}+\mathrm{OH} \bullet \rightarrow \mathrm{HNO}_{2} \\
& \mathrm{HNO}_{2}+\mathrm{OH} \cdot \rightarrow \mathrm{NO}_{2}+\mathrm{H}_{2} \mathrm{O} \\
& \mathrm{NO}_{2}+\mathrm{OH} \cdot \rightarrow \mathrm{NO}_{3}^{-}+\mathrm{H}^{+}
\end{aligned}
$$

The generated superoxide can be also attacked by the following routes:

$\mathrm{O}_{2}^{-}+\mathrm{H}^{+} \rightarrow \mathrm{HO}_{2}$

$\mathrm{NO}+\mathrm{HO}_{2} \rightarrow \mathrm{NO}_{3}^{-}+\mathrm{H}^{+}$

However, due to the lack of sufficient acidic environment and the superoxide generation in the conduction band (NO is adsorbed in the valence band), it is very difficult for the superoxide to undergo the reaction. Therefore, it can be seen that NO is mainly oxidized by the produced radicals firstly to $\mathrm{NO}_{2}$ and finally to $\mathrm{NO}_{3}^{-}$[26].

A pre-treatment was applied prior to the photocatalytic efficiency assessment to further improve the photocatalytic efficiency of the prepared coatings. The pre-treatment was carried out by irradiating the samples by UV light for a certain period $(5,10$ or $24 \mathrm{~h}$ ) in order to degrade the possible hindering layer, and to expose the photocatalytic particles to the environment. The light source was composed of three fluorescent tubes of $25 \mathrm{~W}$ each, emitting highconcentrated UV-A radiation in the range of $300-400 \mathrm{~nm}$ operating under the intensity of $10 \mathrm{~W} / \mathrm{m}^{2}$. The ability to degrade pollutants was used as an indicator for the evaluation of the pre-treatment. The samples were embedded in the plug-flow reactor, as shown in Fig. 2, irradiated by UV light and $1 \mathrm{ppm}$ of NO was introduced in the meantime. The concentration development of the model pollutant was observed. The pre-treatment efficiency evaluation was initially performed on the SC40 coated on the carrier. Furthermore, this was performed on the PC40 and the coatings containing binder SC10-30 and PC10-30.

The photocatalytic efficiency experiments were performed initially on PC40 and SC40 applied on wallpaper. The samples were firstly tested without any pre-treatment [27]. A model pollutant concentration of $1 \mathrm{ppm}$ (nitric oxide), flow rate of $3 \mathrm{~L} / \mathrm{min}$ or $1.5 \mathrm{~L} / \mathrm{min}$ and a visible light irradiation of about $10 \mathrm{~W} / \mathrm{m}^{2}$ were applied. Furthermore, the PC10-40 and the pre-treated SC10-40 samples were tested for photocatalytic efficiency. A model pollutant concentration of $0.5 \mathrm{ppm}$ was used to simulate the real conditions. The SC10-40 samples were tested under variable flow rates $(1,2,3 \mathrm{~L} / \mathrm{min})$ in order to observe the effect of the flow rate on the photocatalytic efficiency. Finally, in order to assess pre-treatment efficiency in terms of PCO efficiency of the coating formulations containing SC40, a prolonged UV pre-treatment of $24 \mathrm{~h}$ was performed.

The $24 \mathrm{~h}$ UV pre-treatment was performed on two samples: SC40 and SC30. A steady UV irradiation, about $10 \mathrm{~W} / \mathrm{m}^{2}$, was applied during the pre-treatment period. Afterwards, samples were tested for the de- $\mathrm{NO}_{x}$ efficiency under visible light irradiation and two different flow rates ( 1.5 and $3 \mathrm{~L} / \mathrm{min}$ ) were used to investigate the effect of the flow rate on the degradation.

\section{Results}

\subsection{Photocatalyst dispersion}

The particle size distribution results of the samples containing KC7000 (KC1 and KC2) showed that the particle size did not change with the $\mathrm{pH}$ modification, although the zeta potential changed considerably. The stability of dispersion was poor in both cases, since the particles tend to set already after $30 \mathrm{~min}$, due to the presence of large agglomerates with an average particle size of about $2 \mu \mathrm{m}$. The unmodified suspension of KC7000 (KC1) was then chosen for further testing. The particle size of SC was measured in the nano-range with the average particle diameter of about $63 \mathrm{~nm}$. The measured particle size along with the $\zeta$-potential value indicated that the suspension was stable, based on the assumption that for sub-micron particles Brownian motion is usually significant to overcome the effect of gravity [28]. Table 2 shows the results of $\mathrm{pH}, \mathrm{PSD}$ and $\zeta$ potential measurements of $\mathrm{KC} 1, \mathrm{KC} 2$ and SC. These results suggest that stabilized nano-scale SC is more suitable than the micro-scale KC7000 due to its optical properties, as mentioned by Allen et al. [22].SC should also exhibit a higher photocatalytic activity, because of its enhanced dispersion in the matrix. Results also revealed that high-energy mixing is not sufficient, even along with $\mathrm{pH}$ modification, to break the agglomerates of the tested photocatalyst.

\subsection{Elemental analysis}

Table 3 lists the determined chemical composition of TC and SC40. A certain amount of silica ( $6.1 \%$ by mass) is contained in the top coating (TC), which could be beneficial for the durability of the coating, the dispersion and the air pollutants removal efficiency of the photocatalyst. The amount of the silica could play an important role in terms of durability when photocatalyst is applied and it will be studied in the future. The analysis of SC40 proved the purity of the suspension that contains $98 \%$ of $\mathrm{C}-\mathrm{TiO}_{2}$ plus several impurities probably introduced during the preparation (milling).

\begin{tabular}{|c|c|c|c|c|c|c|c|c|c|c|c|}
\hline & $\mathrm{SiO}_{2}$ & $\mathrm{SO}_{3}$ & $\mathrm{TiO}_{2}$ & $\mathrm{Ag}_{2} \mathrm{O}$ & $\mathrm{ZrO}_{2}$ & $\mathrm{Al}_{2} \mathrm{O}_{3}$ & $\mathrm{MgO}$ & $\mathrm{CaO}$ & $\mathrm{Cl}$ & $\mathrm{K}_{2} \mathrm{O}$ & $\mathrm{Br}$ \\
\hline TC & 6.139 & 0.971 & - & - & - & 0.183 & 0.123 & 0.156 & 92.059 & 0.191 & 0.176 \\
\hline SC40 & 0.261 & 0.577 & 98.065 & 0.203 & 0.636 & 0.033 & 0.052 & 0.163 & - & - & - \\
\hline
\end{tabular}

Table 3

Elemental analysis results of TC and SC40. 


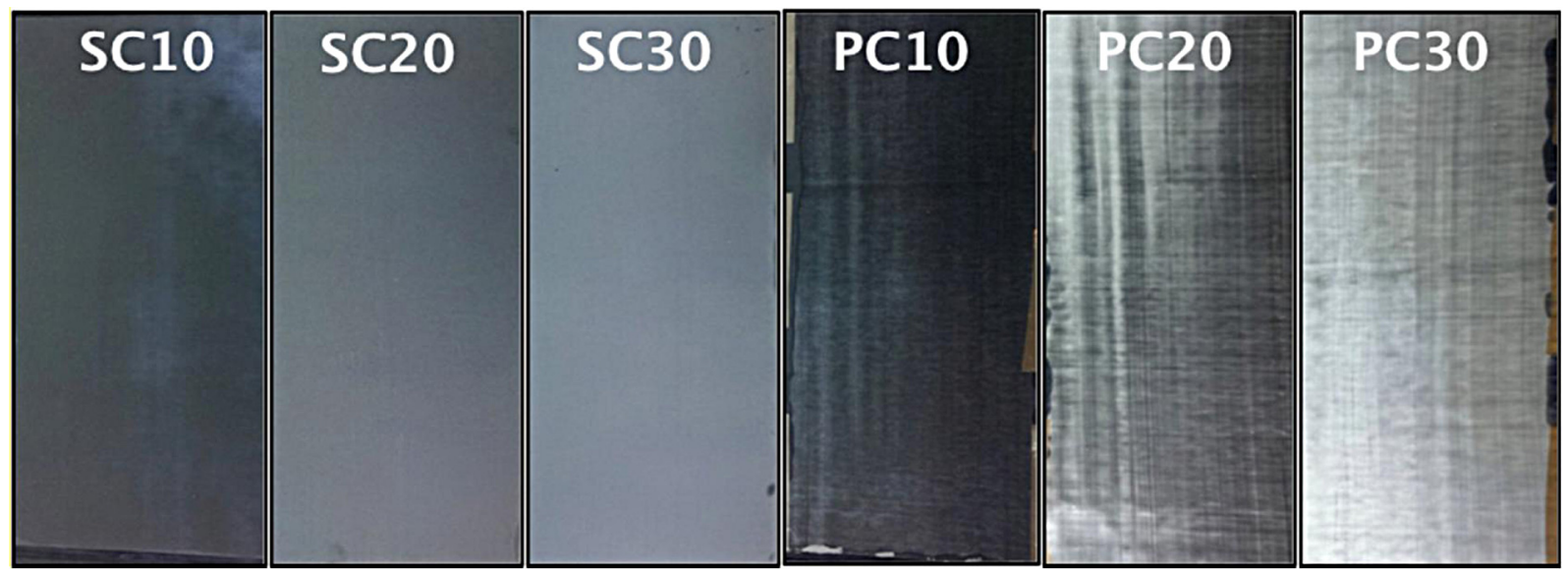

Fig. 3. Photos of the carrier (WP) reference sample (TC) and developed coatings (SC10-40 and PC10-40).

\subsection{Coating preparation}

Fig. 3 depicts the developed coatings (PC10-30 and SC10-30) applied on wallpaper. It is clear that the particle plays an significant role on the aesthetic properties of the coatings. The large particle size of the PC10-30 and the chosen application coating method resulted in a blockage of the voids between the wires, leading to an uneven distribution of the coating along the wallpaper. This was not observed in case when the photocatalytic suspension was applied (SC10-40). The use of the suspension led to prominent benefits in terms of photocatalyst distribution.

\subsection{Morphology analysis}

Fig. 4 shows the SEM images of the base material (TC), PC40 and SC40 applied on the carrier. The SEM images of the wallpaper carrier
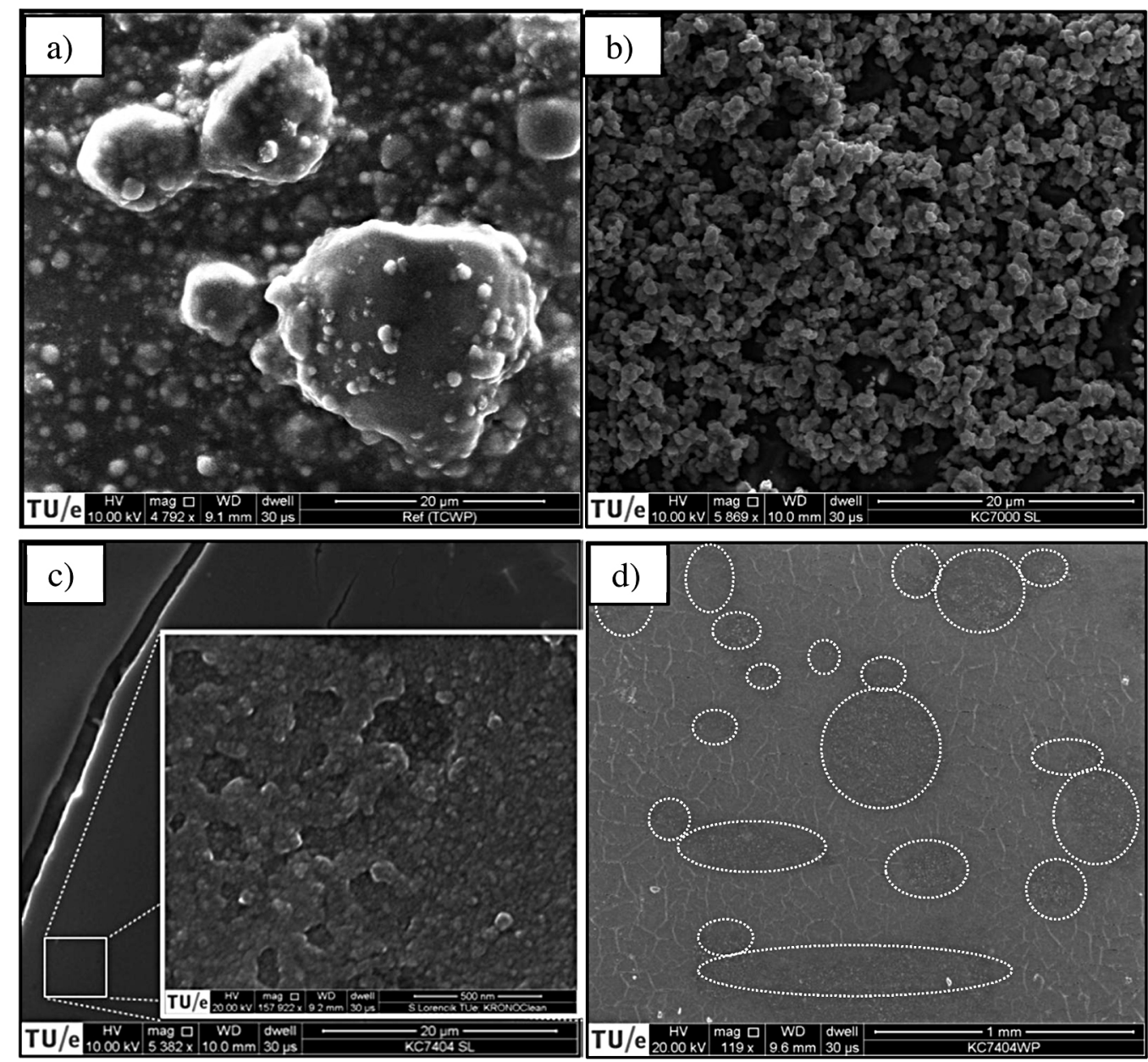

Fig. 4. SEM images of the coatings: a) TC; b) PC40; c) SC40; and d) SC40 (doted area = not coated). 

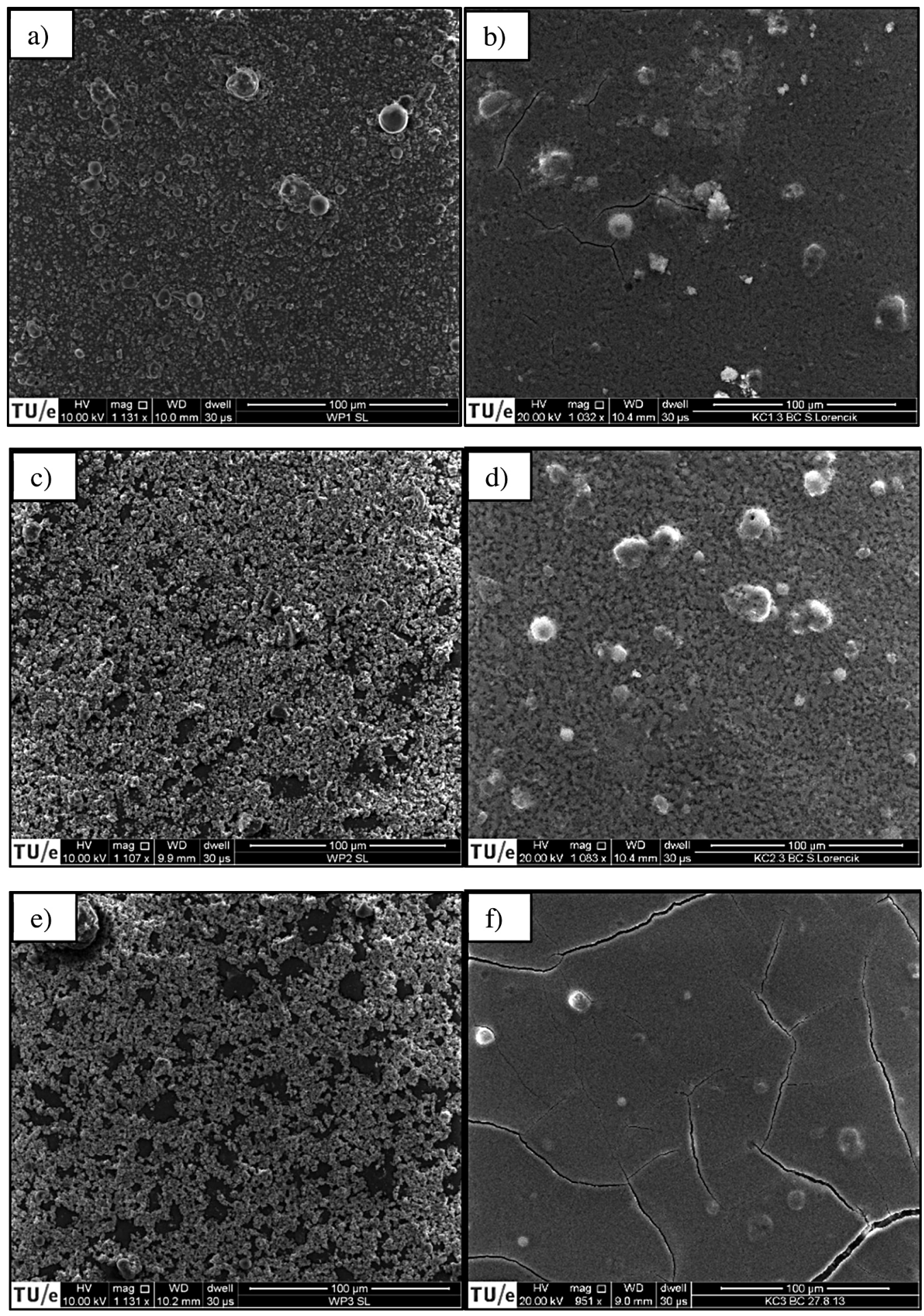

Fig. 5. SEM images of the developed coatings: a) PC10; b) SC10; c) PC20; d) SC20; e) PC30; and f) SC30.

coated with the TC showed the presence of micro-scale particles that could be attributed to the silica that is present in the formulation of the TC, which was analyzed during the XRF analysis $\left(\mathrm{SiO}_{2}\right.$ content $=6.1 \%$ based on the amount of solids). The SEM analysis of PC40 confirmed the presence of large clusters of $\mathrm{C}-\mathrm{TiO}_{2}$ particles with the size around $2 \mu \mathrm{m}$ measured by PSD analysis indicating that relatively commonly used techniques such as the high-shear or ultrasonic are not sufficient to break the particles close to their primary particle size [25]. A solution to that might be an application of other techniques, e.g., bead milling or chemical modification. This can result in uniform and nano-sized particle size distribution of the $\mathrm{C}-\mathrm{TiO}_{2}$ with the average particle size below $100 \mathrm{~nm}$, as observed in the case of SC40. However, due to the high surface tension of the SC40, coatings made only with the SC40 exhibited un-coated parts as can be seen in the Fig. $4 \mathrm{~d}$. This would have a negative effect on the PCO performance, because of the reduced active area. The addition 
Table 4

The $\mathrm{NO}_{x}$ degradation results of the PC40 and SC40 coatings irradiated by visible light irradiation and under various flow rates.

\begin{tabular}{llllll}
\hline Sample & \multicolumn{2}{l}{ PC40 } & & \multicolumn{2}{l}{$\mathrm{SC40}$} \\
\cline { 2 - 3 } & $(3 \mathrm{~L} / \mathrm{min})$ & $(1.5 \mathrm{~L} / \mathrm{min})$ & & $(3 \mathrm{~L} / \mathrm{min})$ & $(1.5 \mathrm{~L} / \mathrm{min})$ \\
\hline $\mathrm{C}_{\text {inlet }}[\mathrm{ppm}]$ & 0.97 & 0.97 & & 0.95 & 0.96 \\
$\mathrm{C}_{\text {outlet }}[\mathrm{ppm}]$ & 0.83 & 0.76 & & 0.95 & 0.95 \\
Degradation [\%] & 14 & 21 & & 0 & 1
\end{tabular}

of the water based TC, containing several wetting agents, can lower the surface tension and improve the wettability of the coating.

A layer of surfactant, which is used to promote the stability of the suspension and prevent re-agglomeration, covers the nanoparticles in SC40. This negatively affects the PCO efficiency of the coating as the photocatalytic particles are hindered from direct contact with reactants. Therefore, further actions need to be done in order to promote the PCO efficiency, as also reported by Kasanen et al. [29]. This will be discussed in the following sections (Section 4.5.2).

The morphology analysis of samples PC10-30 revealed a nonuniform distribution of particles and the presence of micro-scale agglomerates that are not properly immobilized. Due to the microscale of the particles, PC10-30 coatings are opaque in some extent. The addition of SC40 into the TC resulted in a crack formation after the curing and pre-treatment phase, which suggests the necessity for modification of the composition, due to the high amount of additives, or modification of the curing process [30]. The distribution of SC40 in the TC appeared to be uniform, which can be observed in the images as darker spots on the coatings. The distribution of the coatings SC10-30 appeared to be uniform in contrast with the pure SC40 coating (see Fig. 4d). Visually, all coatings made with SC40 were transparent due to the low dosages and the small particle size, which is in line with Scalarone et al. [23], who concluded that if the particle size is around $50 \mathrm{~nm}$, light is transmitted and the acrylic coating retains its characteristic transparency. The SEM analyses performed on the coated samples SC10-30 and PC10-30 are presented in Fig. 5. The images of the PC40 and SC40 are presented in Fig. 4.

\subsection{Photocatalytic efficiency assessment}

\subsubsection{Preliminary evaluation}

Table 4 shows the $\mathrm{NO}_{x}$ degradation results of the PC40 and SC40 applied on wallpaper and tested under visible light irradiation for a duration of one hour under two different flow rates (3 and $1.5 \mathrm{~L} / \mathrm{min}$ ). The de- $\mathrm{NO}_{x}$ results showed that about $14 \%$ of $\mathrm{NO}_{x}$ was degraded by PC40 under the flow rate of $3 \mathrm{~L} / \mathrm{min}$ and $21 \%$ of $\mathrm{NO}_{x}$ was degraded under the flow rate of $1.5 \mathrm{~L} / \mathrm{min}$. The NO degradation was higher $(25 \%$ under the flow rate of $3 \mathrm{~L} / \mathrm{min}$ and $34 \%$ under the flow rate of $1.5 \mathrm{~L} / \mathrm{min}$ ), but the formation of $\mathrm{NO}_{2}$ decreased the over-

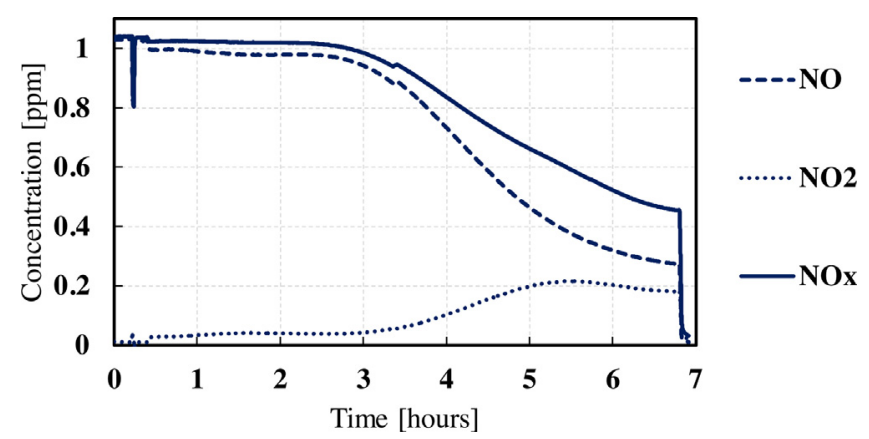

Fig. 6. The $\mathrm{NO}_{x}$ concentration development during the pre-treatment period of SC40.

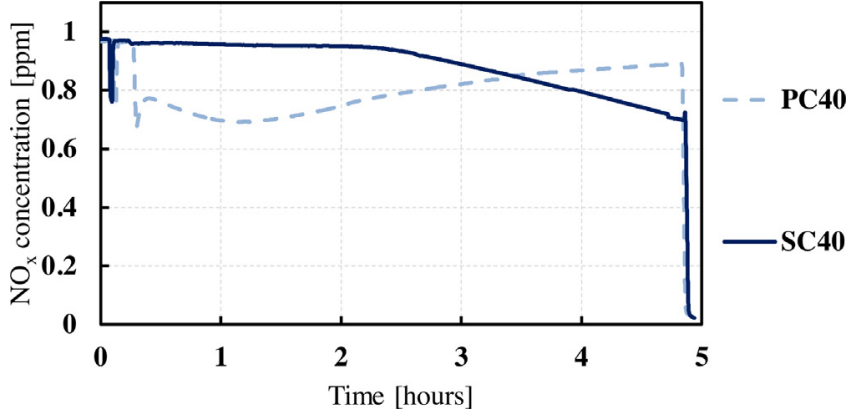

Fig. 7. The $\mathrm{NO}_{x}$ concentration development comparison during the pre-treatment period of PC40 and SC40.

all PCO efficiency. The experiment performed on the SC40 showed very low $\mathrm{NO}_{x}$ degradation, only about $1 \%$ under the flow rate of $1.5 \mathrm{~L} / \mathrm{min}$ was observed. It was assumed that the cause for such a low degradation efficiency was the hindering of the photocatalytic particles by the surfactant that is necessary to stabilize the nano-particles due to the strong attractive forces, as discussed in the previous section. This hindering prevented the pollutants to reach the surface of the $\mathrm{TiO}_{2}$ particles and this suggested that a treatment step was highly necessary.

\subsubsection{Pre-treatment}

An ultraviolet (UV) treatment was chosen to be applied to the developed coating prior to the visible light assessment. This was done in order to remove the surfactant from the photocatalyst, expose the photocatalytic particles and activate the coating. Fig. 6 shows graphically the $\mathrm{NO}, \mathrm{NO}_{2}$ and $\mathrm{NO}_{x}$ concentration development results during the pre-treatment of the SC40 sample.

The pre-treatment showed no efficiency in the first two hours (no NO degradation). After this period, the NO concentration started to decrease, which signified that the material started to be photocatalytically active. The pre-treatment evaluation was terminated after $7 \mathrm{~h}$. The $\mathrm{NO}_{x}$ degradation was 55\% and no deactivation took place during the experiment. The $\mathrm{NO}_{x}$ concentration had a decreasing trend in that time, which suggests necessity for an optimized pre-treatment duration or applied UV intensity.

In order to assess the effect of the pre-treatment duration, 5 and $10 \mathrm{~h}$ long pre-treatments were chosen. The $5 \mathrm{~h}$ pre-treatment was chosen by using the requirement stated in ISO 22197-1 as a reference, where a $5 \mathrm{~h} \mathrm{UV}$ irradiation is used for the degradation organic matter on tested sample. The $10 \mathrm{~h}$ pre-treatment was applied in order to assess the effect a longer pre-treatment possesses on the photocatalytic efficiency. All the samples were initially pre-treated for $5 \mathrm{~h}$ and the concentration development of $\mathrm{NO}_{x}$ in time was monitored. All samples prepared with KC7000 powder (PC10-40) showed a rapid initial degradation, followed by a quick decrease of the PCO efficiency, resulting in a low degradation even in the case of PC40, where no binder was applied. This deactivation can be attributed to the loss of active sites due to the large particle size [31]. All samples prepared with SC40 (SC10-40) showed no $\mathrm{NO}_{x}$ degradation for about $2 \mathrm{~h}$. After this period, particles were exposed and the PCO activity was enhanced. Fig. 7 shows the $\mathrm{NO}_{x}$ concentration development on PC40 and SC40 during the pre-treatment period.

\subsubsection{PCO efficiency assessment}

Table 5 shows the $\mathrm{NO}_{x}$ degradation results of the developed coatings under the flow rate of $1.5 \mathrm{~L} / \mathrm{min}$ irradiated by visible light. The PC10 was able to degrade only $1 \%$ of $\mathrm{NO}_{x}$. However, high de$\mathrm{NO}_{x}$ efficiency results of $12 \%$ and $53 \%$ were observed for the samples PC20 and PC30, respectively. The de- $\mathrm{NO}_{x}$ efficiency of the samples 
Table 5

The $\mathrm{NO}_{x}$ degradation results of the developed coatings during the de- $\mathrm{NO}_{x}$ assessment under the flow rate of $1.5 \mathrm{~L} / \mathrm{min}$ irradiated by visible light irradiation.

\begin{tabular}{llll}
\hline Sample & $\mathrm{NO}_{x}$ degradation [\%] & Sample & $\mathrm{NO}_{x}$ degradation [\%] \\
\hline PC30 & 53.2 & $\mathrm{SC} 30$ & 5.0 \\
PC20 & 11.9 & $\mathrm{SC} 20$ & 1.9 \\
PC10 & 1.0 & $\mathrm{SC} 10$ & 0.5 \\
\hline
\end{tabular}

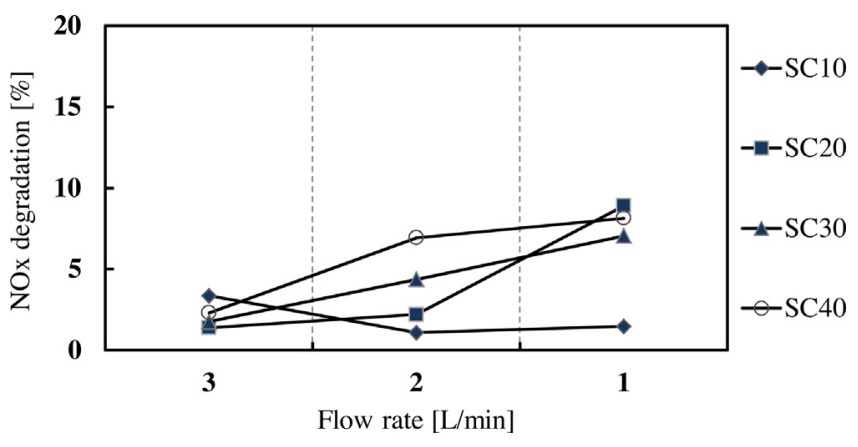

Fig. 8. $\mathrm{NO}_{x}$ degradation efficiencies of $\mathrm{SC} 10-40$ pre-treated for $5 \mathrm{~h}$ tested under various flow rates.

prepared with SC40 was significantly lower with the highest $\mathrm{NO}_{x}$ degradation of only $5 \%$ measured for sample $\mathrm{SC} 30$ of $\mathrm{C}-\mathrm{TiO}_{2}$. The photocatalytic assessment of TC applied on wallpaper showed no NO concentration decreases, which suggested that no photocatalytic reaction took place.

Various flow rates were applied during the photocatalytic assessment of the SC10-40 samples. The flow rate was set to 1-3 L/min designated L1-L3, respectively. Each sample was tested under dark conditions in order to analyze the adsorption of model pollutant on the coatings. The adsorption of NO was tested for the same duration as the photocatalytic test prior to and after the pretreatment, and the results were: $0.5 \%$ for SC10; $1.3 \%$ for SC20; 0.2 for SC30 and $0.1 \%$ for SC30 before the pre-treatment and $0.2 \%$ for SC10; $1.0 \%$ for SC20; $1.1 \%$ for SC30 and $0.9 \%$ for SC40 after the pretreatment. Figs. 8 and 9 shows the $\mathrm{NO}_{x}$ degradation efficiencies of the SC10-40 pre-treated for 5 and $10 \mathrm{~h}$ tested under various flow rates. Coatings containing TC and photocatalyst are labeled with filled marker, SC40 is labeled with empty marker in order to highlight that is does not contain TC. Several conclusions can be made based on these results: (1) the pre-treatment had a significant effect on the photocatalytic efficiency of the samples; (2) longer pre-treatment resulted in better photocatalytic efficiency; (3) the best performing samples were SC30 and SC40; and (4) flow rate modification resulted in significant enhancement of the pollutant degradation.

Fig. 10 shows the $\mathrm{NO}_{x}$ concentration development of the SC40 and SC30 coating applied on wallpaper tested under the flow rate

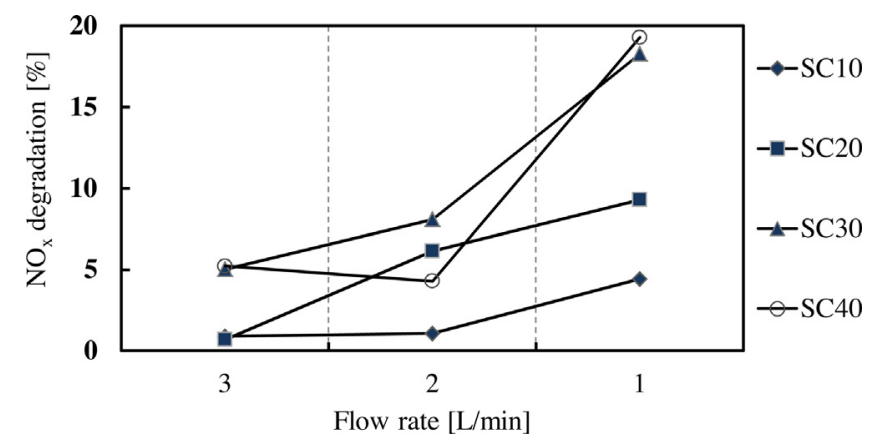

Fig. 9. $\mathrm{NO}_{x}$ degradation efficiencies of $\mathrm{SC} 10-40$ pre-treated for $10 \mathrm{~h}$ tested under various flow rates.

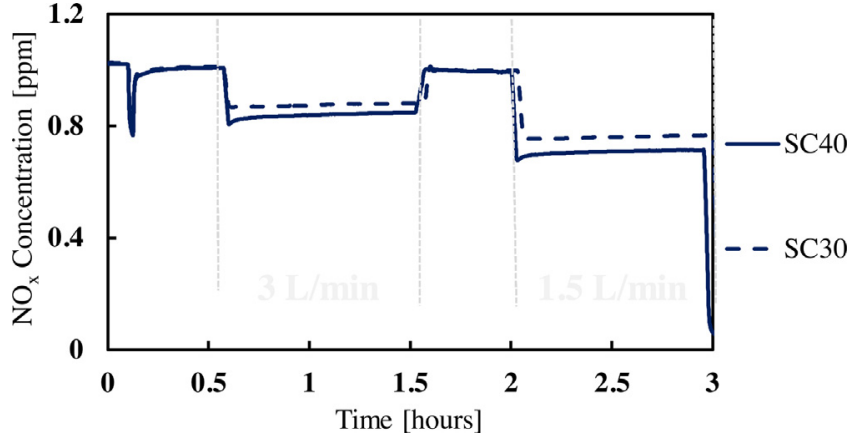

Fig. 10. The $\mathrm{NO}_{x}$ concentration development of the SC40 and SC30 coatings during the de- $\mathrm{NO}_{x}$ assessment irradiated by visible light irradiation and under various flow rates.

of $3 \mathrm{~L} / \mathrm{min}$ and $1.5 \mathrm{~L} / \mathrm{min}$ and initial NO concentration of $1 \mathrm{ppm}$. The de- $\mathrm{NO}_{x}$ experiment of the samples pre-treated for $24 \mathrm{~h}$ revealed significantly higher degradation efficiencies than the ones preconditioned for $5 \mathrm{~h}$. The de- $\mathrm{NO}_{x}$ results for pure SC40 were 16 and $28 \%$; and for SC30 were 13 and $23 \%$ for 3 and $1.5 \mathrm{~L} / \mathrm{min}$, respectively. The long pre-treatment time, however, is not realistically feasible due to the high energy requirements. The lower flow rate represented more closely the real conditions, which resulted in better representation of the real performance of the coatings. The testing method of such a passive photocatalytic materials should be modified in order to obtain results representing real indoor conditions, as was also reported by Ifang et al. [32].

\section{Discussion}

The dispersed $\mathrm{C}-\mathrm{TiO}_{2}$ powder ( $\mathrm{PC} 40$ ) and $\mathrm{C}-\mathrm{TiO}_{2}$ suspension (SC40) were directly immobilized into the water-based top-coating under different proportions, as it is cost effective and operationally relatively easy $[18,19]$. Results revealed micro-scale agglomerates in case of PC40 dispersed in aqueous media, and nano-scale particles in case of SC40 suspension. The particle size plays a significant role on the stability, transparency and PCO activity of the PC40 during the de- $\mathrm{NO}_{x}$ experiments due to the strong deactivation. The SC40 suspension was stable due to the small particle size and high zeta potential value. The nano-particle size resulted in transparent coatings.

The photocatalytic results revealed higher activity of the micro-sized PC40 under visible light irradiation compared to the nano-sized SC40. This is in disagreement with Allen et al. [22], who concluded that the photocatalyst with smaller particle size exhibits higher photocatalytic activity. A reason to such a low degradation in case of SC40 was the coverage of the photocatalytic particles by the surfactants. This resulted in a necessity to activate the product. The activation was done by UV pre-treatment of the SC40 applied on wall covering in order to degrade the surfactant covering the photocatalytic particles and to expose the particles to the environment. Another methodology was applied by Kasanen et al. [29], who incorporated $\mathrm{TiO}_{2}$ particles into the polyurethane resin, and an oxygen-plasma treatment was used in order to expose photocatalytic particles. This treatment could, however, be difficult to transfer into real production. The de- $\mathrm{NO}_{x}$ results of the SC40 during the UV pre-treatment showed that the PCO efficiency was promoted already after $2 \mathrm{~h}$. Nevertheless, the optimal duration and/or UV intensity still needs to be determined and optimized.

A series of coatings applying PC40 or SC40 were formulated and tested for PCO efficiency and morphology. The results showed that coatings prepared by incorporation of PC40 formed large, microscale, agglomerates, which affect the distribution of the particles and the transparency of the coating as well. The coatings contain- 
ing SC40 showed nano-scale particles, with even distribution due to the strong stabilization of the suspension. However, the high surface tension of the suspension led to the formation of unevenly distributed coating.

The de- $\mathrm{NO}_{x}$ experiments were performed according to the ISO 22197-1 with the flow rate of $1.5 \mathrm{~L} / \mathrm{min}$, under visible light irradiation on the PC10-30 and SC10-30 samples. The PC coatings showed significantly higher $\mathrm{NO}_{x}$ degradation (53\% for PC30) than SC coatings (5\% for SC30). Further experiments on the SC10-40 samples under various flow rates and two pre-treatment durations (5 and $10 \mathrm{~h}$ ) revealed the necessity of fitted UV pre-treatment duration based on the composition of the coating and application of suitable testing conditions in order to more representatively interpret the performance of the developed coating. The NO adsorption experiments performed on the samples under dark conditions showed similar results before and after pre-treatment. This suggests that there is no significant effect of pre-treatment on the NO adsorption and that the $\mathrm{NO}_{x}$ concentration decrease is purely caused by photocatalytic reaction.

A prolonged pre-treatment carried out on SC40 and SC30 samples showed significant improvement of $\mathrm{NO}_{x}$ degradations (28\% for SC40 and 23\% for SC30). The obtained results are higher than some results on different substrates [4,22].

The ISO standard 22197-1 does not represent realistic indoor conditions (high pollutant concentration, UV irradiation, high flow rate, geometry) as was reported also elsewhere [32]. Moreover, the pollutant conversion is different under such conditions [4] and also does not represent the behavior of the photocatalytic product applied indoors. In this research, the conditions were modified in order to approach indoor conditions closer. A different approach to test such a passive photocatalytic product, such as batch-type reactor, could be beneficial to more accurately assess the photocatalytic efficiency potential for the indoor environment application.

Moreover, in order to obtain better results in real indoor application, optimization of the indoor lightning conditions to promote the photocatalytic efficiency is suggested. Since the cut-off wavelength of the $\mathrm{C}-\mathrm{TiO}_{2}$ extends only to the visible bluish light range [25], the combined effect of UV and visible light to better activate the photocatalytic reactions would be beneficial as suggested in $[4,25]$. Another possible solution might be the utilization of different light sources, such as light-emitting diodes (LEDs), which can emit light with a very narrow wavelength that corresponds to the absorption spectrum of the applied photocatalyst.

\section{Conclusion}

This article addresses the development of a functional waterbased photocatalytic coating for improving the indoor air quality. Visible-light responsive photocatalysts, in a form of powder or suspension, were chosen for the direct incorporation into a commercially used water-based coating. The effect of the incorporation on the morphology and photocatalytic efficiency was analyzed. A previously developed plug-flow experimental setup [4] was used for the assessment of photocatalytic efficiency in accordance with the ISO 22-197-1. The visible light irradiation was applied as a light source.

The experimental results led to the following conclusions:

- The coatings containing $\mathrm{C}-\mathrm{TiO}_{2}$ incorporated in a powder form possess a high photocatalytic efficiency ( $53 \%$ de- $\mathrm{NO}_{x}$ ). However, the formation of highly agglomerated clusters led to poor visual properties and poor incorporation of the photocatalyst.

- The coatings containing $\mathrm{C}_{-} \mathrm{TiO}_{2}$ incorporated in a suspension form showed significantly improved visual properties and promising photocatalytic efficiency after the application of a pretreatment.

- The pre-treated samples (containing TC) tested under more realistic conditions showed maximal photocatalytic de- $\mathrm{NO}_{x}$ efficiencies from $7 \%$ de- $\mathrm{NO}_{x}$ after a $5 \mathrm{~h}$ UV pre-treatment and $18 \%$ after a $10 \mathrm{~h}$ UV pre-treatment for coatings containing $30 \%$ of $\mathrm{C}-\mathrm{TiO}_{2}$.

- Issues in application of $\mathrm{C}-\mathrm{TiO}_{2}$ in a suspension form, such as the excess of additives in the coating formulations and the pretreatment optimization, need to be further addressed.

\section{Moreover, this study reveals that:}

- A more suitable testing method should be applied in case of passive photocatalytic materials, such as photocatalytic wallpaper coating, in order to more reliably predict their real performance;

- A method representing indoor air conditions, applying lower flow rate ( $<1 \mathrm{~L} / \mathrm{min}$ ), lower concentration of model pollutant (ppb levels [1]), mixture of the pollutants (organic and inorganic), lower visible light intensity and mixing should be considered to better interpret the performance of potocatalytic materials under real conditions.

\section{Acknowledgements}

This research was carried out under the project M81.7.10405 in the framework of the research program of the Materials innovation institute $\mathrm{M} 2 \mathrm{i}$. The authors wish to express their gratitude to the following sponsors of the Building Materials research group at TU Eindhoven: Rijkswaterstaat Grote Projecten en Onderhoud, Graniet-Import Benelux, Kijlstra, Betonmortel, Struyk Verwo, Attero, Enci, Rijkswaterstaat Zee en Delta- District Noord, Van Gansewinkel Minerals, BTE, V.d. Bosch Beton, Selor, GMB, Geochem Research, Icopal, BN International, Eltomation, Knauf Gips, Hess AAC Systems, Kronos, Joma, CRH Europe Sustainable Concrete Centre, Cement\&BetonCentrum, Heros, Inashco (in chronological order of joining).

\section{References}

[1] World Health Organization, WHO. Guidelines for Indoor Air Quality: Selected Pollutants, 2010.

[2] C.C.L. Tan, K.N. Finney, Q. Chen, N.V. Russell, V.N. Sharifi, J. Swithenbank, Indoor Built Environ. 22 (2012) 471

[3] M.M. Ballari, H.J.H. Brouwers, J. Hazard. Mater. 254 (2013) 406.

[4] Q.L. Yu, H.J.H. Brouwers, Appl. Catal. B Environ. 92 (2009) 454.

[5] T. Martinez, A. Bertron, G. Escadeillas, E. Ringot, V. Simon, Build. Environ. 71 (2014) 186

[6] M. Sleiman, J.-M. Chovelon, P. Conchon, C. Ferronato, Appl. Catal. B Environ. 86 (2009) 159.

[7] Y. Paz, Appl. Catal. B Environ. 99 (2010) 448

[8] K. Nakata, A. Fujishima, J. Photochem. Photobiol. C Photochem. Rev. 13 (2012) 169.

[9] C.-S. Lee, J. Kim, J.Y. Son, W. Choi, H. Kim, Appl. Catal. B Environ. 91 (2009) 628.

[10] G. Hüsken, M. Hunger, H.J.H. Brouwers, Build. Environ. 44 (2009) 2463.

[11] L. Senff, D.M. Tobaldi, S. Lucas, D. Hotza, V.M. Ferreira, J.A. Labrincha, Composits Part B 44 (2013) 40.

[12] M. Radeka, S. Markov, E. Lončar, O. Rudić, S. Vučetić, J. Ranogajec, J. Eur. Ceram. Soc. 34 (2014) 127.

[13] X. Zhao, L. Lv, B.W. Pan Zhang, S. Zhang, Q. Zhang, Chem. Eng. J. 170 (2011) 381.

[14] M. Langlet, M. a Kim, Audier, C. Guillard, J. Herrmann, Thin Solid Films 429 (2003) 13.

[15] A. Goldschmidt, H.-J. Streitbeger, BASF Handbook on Basics of Coating Technology (American Coatings Literature), Vincentz, 2003.

[16] A. Mathiazhagan, R. Joseph, Int. J. Chem. Eng. Appl. 2 (2011).

[17] M. Gohin, I. Maurin, T. Gacoin, J.-P. Boilot, J. Mater. Chem. 20 (2010) 8070.

[18] S. Singh, H. Mahalingam, P.K. Singh, Appl. Catal. A Gen. 462 (2013) 178.

[19] S.-P. Yew, H.-Y. Tang, K. Sudesh, Polym. Degrad. Stab. 91 (2006) 1800.

[20] M. Sökmen, I. Tatlıdil, C. Breen, F. Clegg, C.K. Buruk, T. Sivlim, S. Akkan, J. Hazard. Mater. 187 (2011) 199

[21] C.-M. Chan, J. Wu, J.-X. Li, Y.-K. Cheung, Polymer (Guildford). 43 (2002) 2981 
[22] N.S. Allen, M. Edge, J. Verran, J. Stratton, J. Maltby, C. Bygott, Polym. Degrad. Stab. 93 (2008) 1632.

[23] D. Scalarone, M. Lazzari, O. Chiantore, Polym. Degrad. Stab. 97 (2012) 2136.

[24] M. Yianneskis, F. Magelli, A. Liné, N.G. Özcan-Tașkin, G. Padron, A. Voelkel, Chem. Eng. Res. Des. 87 (2009) 468.

[25] S. Bloss, L. Elfenthal, International RILEM Symposium on Photocatalysis, Environment and Construction Materials, Florence, Italy, 2007, pp. 31-38.

[26] Q.L. Yu, M.M. Ballari, H.J.H. Brouwers, Appl. Catal. B Environ. 99 (2010) 58.

[27] ISO 22,197-1:2007 - Fine Ceramics (advanced Ceramics, Advanced Technical Ceramics) - Test Method for Air-Purification Performance of Semiconducting Photocatalytic Materials - Part 1: Removal of Nitric Oxide, n.d.
[28] R.G. Larson, Struct. Rheol. Complex Fluids (1999).

[29] J. Kasanen, J. Salstela, M. Suvanto, T.T. Pakkanen, Appl. Surf. Sci. 258 (2011) 1738.

[30] S. Bloss, Personal Communication within This Project, 2013.

[31] D.F. Ollis Comptes Rendus l'Académie Des Sci. - Ser. IIC - Chem. 3 (2000) 405.

[32] M. Ifang, S. Gallus, R. Kurtenbach, P. Wiessen, J. Kleffmann, Atoms. Environ. 91 (2014) 154. 